\title{
Earthworm Living Conditions and Effects of Earthworms on Soil Parameters
}

\author{
Ming-hua DUAN ${ }^{1}$, Dong-dong GUAN ${ }^{1}$, Ying-yuan PEI ${ }^{1}$, Chang-long ZHOU ${ }^{2}$, Xin PAN $^{2}$, \\ Zhi-dong QIU ${ }^{1 *}$ \\ ${ }^{1}$ Changchun University of Chinese Medicine, Changchun, Jilin, China \\ ${ }^{2}$ Training Corps One of the Aeronautical University, Changchun, Jilin, China
}

\begin{abstract}
The living conditions of earthworms were studied, with the aim of improving our understanding of soil recovery from acidification and of the degradation and aggregation of substances in soil. This information can provide a theoretical basis for solving the problem of excessive heavy metals in agricultural soil. We concluded that earthworms have a strong ability to aid soil recovery and mitigate excessive heavy metals in soil.
\end{abstract}

KEYWORD: acidification; earthworm; habitat; heavy metals; mitigation; soil

Earthworms are common soil invertebrates whose important role in the ecosystem is often overlooked. Their activities improve the soil fertility and structure, adjust the soil microflora balance, and accelerate the decomposition of organic matter. A large number of chemicals, such as commonly used agricultural pesticides, damage the soil structure and leave excessive heavy metals and organic solvent residues in the soil, potentially contaminating foods and drugs produced from crops. This paper reviews the ecology of earthworms and their effects on soil, in order to provide a theoretical basis for further research and practices that will protect our environment.

Soils harbor a rich diversity of soil microorganisms and invertebrates [1]. In order to adapt to the environmental conditions caused by changing water levels in unstable soil, microbes and invertebrates have developed complementary functions that can digest low-quality food resources. Microbes digest [2] complex substances in soil, while invertebrates tunnel through the soil, improving its aeration and structure. These environmental services are important benefits in agricultural land. Meanwhile, agricultural practices such as tillage, harvesting that leaves bare soil, monocropping, and use of pesticides seriously affect soil quality and pose challenges to the survival of soil invertebrates.

\section{EFFECTS OF SOIL FACTORS ON EARTHWORMS}

\subsection{Effects of external factors on earthworms}

Many long-term experiments on soil ecology have been conducted in banana plantations [3]. One study compared the effects of paraquat spray, artificial mechanical weeding, and manual weeding on earthworm populations [4]. None of the methods significantly affected the number of earthworms after two years of monitoring. However, the amount of rainfall, use of organic practices, application of organic mulch, and amount of soil cover do affect the number of earthworms.

\subsection{Effects of tillage on earthworm survival}

Conventional tillage methods limit the movement of earthworms [5], accelerating the degradation of crop straw and reducing the supply of food to earthworms.

These negative effects may be mitigated in agricultural ecosystems by preserving crop residues [6]. In one study from Canada that spanned 15 years, three tillage systems were compared: moldboard plowing/disc harrow, chisel plow or disc harrow, and no tillage. The effects of high vs. low inputs of crop residues were also examined. No tillage was associated with higher earthworm populations than either of the two farming methods, while the amounts of crop residues did not affect the number of earthworms.

Earthworm growth rate in the laboratory is proportional to the amount of organic $\mathrm{C}$ in soils. Therefore, some people advocate adding more organic matter to the soil to increase the soil organic $\mathrm{C}$ content. However, experimental data show that farming practices have a much greater impact on earthworm populations than do nutrients in the soil.

From 2010 to 2012, earthworm populations on four farms were studied in the Netherlands [7]. 
Arable field margin strips (FM) and non-inversion tillage (NIT; a reduced tillage system that loosens subsoil at a depth of $30-35 \mathrm{~cm}$ ) were expected to be associated with higher species abundance in earthworms (epigeics and anecics in particular), as well as higher amounts of soil organic matter and soil moisture than moldboard ploughing (MP), which was conducted in adjacent fields. Earthworm numbers were expected to decrease with distance away from FM into arable MP fields. FM sites contained a mean total earthworm abundance of $284 \mathrm{~m}^{-2}$ and biomass of $84 \mathrm{~g} \mathrm{~m}^{-2}$, whereas adjacent MP arable fields had only 164 earthworms $\mathrm{m}^{-2}$ and $31 \mathrm{~g} \mathrm{~m}^{-2}$.

Aporrectodea rosea, Lumbricus rubellus, $L$. terrestris, and $L$. castaneus were significantly more abundant in FM than in adjacent arable MP soil. However, no decreasing trend with distance from FM was observed in earthworm species abundance. A tillage experiment on the farms with FM showed that relative to MP, NIT significantly increased the mean total earthworm abundance by $34 \%$ to $275 \mathrm{~m}^{-2}$ and mean total earthworm biomass by $15 \%$ to $51 \mathrm{~g} \mathrm{~m}^{-2}$ for overall sampling dates and farms.

\subsection{Impact of animal manure on earthworm survival}

Long-term use of inorganic fertilizers and reduced organic matter inputs reduced agricultural soil acidification [8], strongly affecting nutrient mineralization and the composition of soil organisms. The application of organic fertilizers, such as solid cattle manure (SCM), may solve the problem of soil acidification by providing trace elements to promote plant growth.

In one experiment in a grasslands site,[9] 400 earthworms $/ \mathrm{m}^{2}$ were found in soil prior to the application of SCM, while the total was $700 / \mathrm{m}^{2} 134$ days after the addition of SCM to reduce soil acidification. Relatively high soil $\mathrm{pH}$ and high density will result in high levels of soil biological activity. The addition of earthworms and lime to the soil, whereas the control group received only SCM, increased the recovery of $\mathrm{N}$ by $83 \%$, and further studies have shown that $\mathrm{N}$ is closely related to earthworm density.

After SCM was added, $\mathrm{N}_{2} \mathrm{O}$ emissions increased by $37 \%$. With the continued addition of SCM, the total amount of $\mathrm{N}$ incorporated into the soil as $\mathrm{N}_{2} \mathrm{O}$ was 10 times higher than the amount of $\mathrm{N}$ release.

In acidic soils, the $\mathrm{N}$ mineralization amount, $\mathrm{N}$ uptake from the SCM, soil $\mathrm{pH}$, and earthworm density all increase. These effects stimulate biological activity in the soil, leading to an increase of $\mathrm{N}$ intake.

\section{EFFECT OF EARTHWORMS ON SOIL FEATURES}

\subsection{Earthworms' effect on $\mathrm{N} 2 \mathrm{O}$ emissions}

The processes of nitrification and denitrification release the greenhouse gas $\mathrm{N}_{2} \mathrm{O}$ [10]. The moisture content of the soil is the key factor influencing $\mathrm{N}_{2} \mathrm{O}$ emissions and resulting in the conversion processes of nitrification and denitrification. Under both aerobic and anaerobic conditions, earthworms are reported to increase emissions of $\mathrm{N}_{2} \mathrm{O}$.

Soil was added to ten containers [11] (diameter $10 \mathrm{~cm}$, height $15 \mathrm{~cm}$ ), with constant surface moisture content of either $33 \%$ or $97 \%$, and the presence or absence of earthworms, and transitioned through three cycles of wet and dry. Six treatments with five replicates were conducted. Every 1-3 days, $\mathrm{N}_{2} \mathrm{O}$ emissions were detected. After 69 days, the activity level of denitrifying bacteria in soil was tested. The moisture content of the soil significantly affected $\mathrm{N}_{2} \mathrm{O}$ emissions, and $\mathrm{N}_{2} \mathrm{O}$ emissions peaked during the three cycles of wet and dry.

In the treatment group with $33 \%$ moisture content, $\mathrm{N}_{2} \mathrm{O}$ emissions increased by $50 \%$, whereas in the group with $97 \%$ moisture content, $\mathrm{N}_{2} \mathrm{O}$ emissions decreased by $34 \%$, probably because of $\mathrm{N}_{2} \mathrm{O}$ conversion to $\mathrm{N}_{2}$.

After three cycles of wet and dry, earthworms significantly reduced $\mathrm{N}_{2} \mathrm{O}$ emissions by $82 \%$ and soil denitrification enzyme activity was improved. The interaction of earthworms and soil moisture caused $16 \operatorname{SrRNA}$, nirS, and nos $Z$ gene expression to be higher. After three cycles of wet and dry, $16 S r R N A$ and nos $Z$ gene expression were higher.

Under conditions of high soil moisture, as well as during cycles of wet and dry, earthworms can alter the community structure of denitrifying bacteria, thereby reducing $\mathrm{N}_{2} \mathrm{O}$ emissions.

\subsection{Improvement of soil environment by fermentation}

The soil-like substrate (SLS) technique is a key method for improving the closure of the bioregenerative life support system (BLSS) by recycling the inedible biomass [12] of higher plants. This method involves maintaining an environment at $35{ }^{\circ} \mathrm{C}$ for soil aerobic fermentation for 1 day, followed by $60{ }^{\circ} \mathrm{C}$ for fermentation over 6 days, followed by $30{ }^{\circ} \mathrm{C}$ for fermentation over 3 days. Earthworms are then added to the soil for the next 70 days.

SLS effectively shortens the entire cycle by 13 days and increases the dry weight loss from $24.77 \%$ to $81.1 \%$ [13]. The cellulose and lignin degradation rate was $96.6 \%$ and the divide ratio was $94.6 \%$.

Using SLS, the concentrations of $\mathrm{N}, \mathrm{P}$, and $\mathrm{K}$ are, respectively, $776.1 \mathrm{mg} / \mathrm{L}, 348.0 \mathrm{mg} / \mathrm{L}$ and 7943.0 $\mathrm{mg} / \mathrm{L}$. The method produced a small amount of 
methane and ammonia, but the amounts of the two gases were not cumulative. The technology is suitable for promoting seed germination in plant cultivation. SLS technology will provide the experimental basis for the primary BLSS.

\subsection{Ecological impacts on soil fungi and bacteria}

Experiments on the impacts of earthworms on other soil organisms are divided into two groups by methodology: in the first group, earthworms were added to fresh fruits and vegetables waste, while in the other group[14], earthworms were not added to this type of waste. After five weeks, the effects of these substances on the physicochemical properties of the earthworm were examined.

Starting in the second week, the treatment containing earthworms was associated with a rapid decline in the loss of conductivity and total $\mathrm{C}$ and $\mathrm{N}$, compared with the treatment that did not have earthworms. Quantitative polymerase chain reaction analysis showed that during the degradation process, the presence of earthworms significantly increased concentrations of bacteria and fungi.

In addition, denaturing gradient gel electrophoresis and DNA sequencing analysis showed that earthworms, by expanding the diversity [15] of actinomycetes, significantly alter the bacterial community structure and promote the growth of fungi such as ascomycetes and bacteria such as Bacteroides and Proteobacteria. Earthworms change the bacterial and fungal community structure, thereby changing the decomposition pathways of fresh fruits and vegetables.

\subsection{Degradation of chemical substances in soil}

In another experiment, the DNA-probe isotope method was used to reveal the degradation of pentachlorophenol [16] in soil in the presence of two earthworm species (Amynthas robustus Perrier and Eisenia fetida Savigny). The results showed that the degree of dispersion of soil particles and organic matter affected the degradation rate [17]. The two earthworm species improved soil pentachlorophenol degradation rate and basal respiration.

DNA-isotope probe results showed that the number of Klebsiella, Cupriavidus, and Aeromonas spp. and Burke Hall with 13C-labeling is more abundant than with $12 \mathrm{C}$-labeling in soil. These different species of bacteria play a role in the degradation of pentachlorophenol.

During the degradation of pentachlorophenol, earthworm species increase, which accelerates the degradation of pentachlorophenol by soil bacteria.

\subsection{Aggregation of metal ions}

Other studies have examined the effects of adding animal manure and mushroom residue to compost containing earthworms and studied the effects [18] of earthworms on the aggregation of heavy metals. Earthworm activity accelerated the decay of organic matter mineralization.

When increased amounts of heavy metals were present in compost, such as arsenic, lead, copper, and zinc, adding earthworms significantly reduced [19] the activity of heavy metals. The activity of heavy metals depended not only on earthworms' biological activities, but also on the binding of these metals to plants.

Earthworm excrement can increase the nutritional quality of the soil for plants and can alleviate the risk of heavy metals in agricultural organic wastes. The addition of compost and earthworm feces is the classic method of treating sludge and significantly affects the distribution and form of heavy metals.

In the experiment, industrial sludge was contaminated with arsenic $(396 \pm 1 \mathrm{mg} / \mathrm{kg})$ [20]. Three treatments were compared, in which compost, earthworm excrement, or a mixture of compost and earthworm excrement were added. In each treatment, the form of arsenic, arsenic mobility, and the effect on bioavailability were evaluated. The earthworm excrement was produced by E. fetida.

The ratio of added materials was sludge: horse manure: grass $=3: 6: 1$. A $0.1 \mathrm{~mol} / \mathrm{L}$ solution of $\mathrm{NH}_{4} \mathrm{COOCH}_{3}$ was used as the extract to assay the content of binding arsenic and free arsenic.

The results showed that adding both compost and earthworm excrement to sludge decreased the amount of free arsenic and arsenic activity. Of the three treatments, the mixture of compost and earthworm excrement had the greatest effect on the amount of arsenic and the arsenic form.

In another experiment, cow dung and earthworms were added to paper mill wastewater to investigate the effect of earthworms on the elimination of heavy metals.

There were seven experimental groups: (1) 100\% cow dung, (2) wastewater: cow dung $=1: 3$, (3) wastewater: cow dung $=1: 2$, (4) wastewater: cow dung $=1: 1$, (5) $100 \%$ wastewater, (6) wastewater: cow dung $=3: 1$, and (7) wastewater: cow dung $=$ $2: 1$. The experiment lasted 60 days and measured the amounts of different heavy metals that were converted.

The results were as follows: cadmium (32\%$37 \%$ ), cesium $(47.3 \%-80.9 \%)$, copper (68.8\%$88.4 \%)$, and lead (95.3\%-97.5\%). All concentrations of heavy metals decreased significantly, and the total amounts of $\mathrm{N}, \mathrm{P}$, and $\mathrm{K}$ increased significantly.

Worms have a strong ability to accumulate heavy metal ions. The amounts of various metal ions in the organs of worms are as follows: lead (8.84\%- 
9.69\%), cadmium $(2.31 \%-2.71 \%)$, cesium $(20.7 \%-$ $35.9 \%)$, and copper $(9.94 \%-11.6 \%)$.

The ratios of wastewater: cow dung $=2: 1$ or $3: 1$ were the most suitable ratios to eliminate heavy metals, while ensuring a high growth rate in earthworms. The rates of elimination of heavy metals followed the order cadmium > cesium > lead > copper.

In summary, experimental results show that adding both animal manure and earthworms is the most effective method to remove heavy metals from the wastewater produced during papermaking.

\subsection{Pathway of metal ions ingested by earthworms}

Earthworms ingest soil particles and soil pore water through their skin or mouths. It is important to study the pathway followed by metal ions in the soil [13] to assess the biological responses of earthworms to soil contaminants.

When earthworms' bodies were sealed using chemical glue to prevent them from absorbing soil particles and pore moisture, earthworms continued to show good viability and activity levels after 6 days and had not digested any soil during this time. When sealed earthworms and a control group of earthworms were placed in sewage, they absorbed equal amounts of heavy metals. Therefore, the intake of soil pore water does not affect the aggregation of heavy metals in earthworms' bodies.

In contaminated soil, sealed earthworms and control group earthworms showed similar absorption of cadmium, copper, and lead. However, the rates of zinc accumulation and elimination decreased significantly in sealed earthworms. The aggregation of copper and lead were completely dependent on dermal absorption.

Cadmium and zinc concentrations within earthworm organs were $0 \%-17 \%$ and $21 \%-30 \%$, respectively, reflecting absorbance through intake.

The leather gathering system has become an important channel by which to collect heavy metals. This method of sealing is a useful way to measure the absorption of nutrients and pollutants.

\section{PROPERTIES OF EARTHWORMS}

\subsection{Secretion of fluids by earthworms}

Autofluorescence of living cells occurs when cells containing a fluorescent substance are stimulated and the substance emits fluorescence. One type of organism produces light fluorescence [23], as well as the mucus secreted by all earthworms. The fluorescent substance has been studied using fluorescence microscopy and video microscopy.

After experiencing chemical or electrical stimulation, earthworms secrete yellow mucus from a site located near the mouth. The fluorescent substance is stored in a vesicle membrane. It is released from the body in complete stable vesicles formed into a particulate material or a chain. This phenomenon takes place in least four phases: vesicle release, particle formation, muscle contraction, and organizational chain.

\subsection{Use of biomimetic sensors in earthworm studies}

A sensor [24] can imitate invertebrates as receptors in vivo and in vitro. The PVDF membrane sensor is flexible, highly sensitive, and easily integrated into different shapes. It possesses a smart shape memory alloy that drives its configuration, and a scalable perforated PVDF chain can be embedded into mini robots shaped like segmented crawling worms with silicone casings. This technology was used to create a four-part mini-robot with a sensor skin. Dispersed silica sensing parts and induction experiments showed that bionic robot mini PVDF sensors could detect changes in vivo and in vitro, so they could mimic earthworm feelings and simulation capabilities.

\section{REFERENCES}

[1] Qinfeng Guo. Climate change and biodiversity conservation in Great Plains agroecosystems. Global Environmental Change. 2000, 10 (4): 289-298

[2] P. Lavelle, F. Moreira, A. Spain. Biodiversity: Conserving Biodiversity in Agroecosystems. Encyclopedia of Agriculture and Food Systems, 2014, 41-60

[3] Ma. Abegail Fusilero, Jhoanavi Mangubat, Richie Eve Ragas, et al. Weed management systems and other factors affecting the earthworm population in a banana plantation. European Journal of Soil Biology, 2013, 56, 89-94

[4] Clotilde Sagot, Jean-Jacques Brun, Jean-Luc Grossi. Earthworm distribution and humus forms in the development of a semi-natural alpine spruce forest. European Journal of Soil Biology. 1999, 35 (4): 163-169

[5] Sissel Hansen, Freddy Engelstad. Earthworm populations in a cool and wet district as affected by tractor traffic and fertilization. Applied Soil Ecology. 1999, 13 (3): 237-250

[6] Nikita S. Eriksen-Hamel, Alicia B. Speratti, Joann K. Whalen, et al. Earthworm populations and growth rates related to long-term crop residue and tillage management. Soil and Tillage Research,2009,104 (2): 311-316

[7] S. J .Crittenden, E. Huerta, R. G. M. de Goede. et al. Earthworm assemblages as affected by field margin strips and tillage intensity: An on-farm approach. European Journal of Soil Biology, 2015, 66: 49-56

[8] P. Mc Granaghan, J. C. Davies, G. W. Griffith, D. R. Davies.et al. The survival of anaerobic fungi in cattle faeces. FEMS Microbiology Ecology. 1999, 29 (3): 293300

[9] Muhammad Imtiaz Rashid. Ron G.M.de Goede, Gabriel A. Corral Nunez.et al. Soil pH and earthworms affect herbage nitrogen recovery from solid cattle manure in production grassland. Soil Biology and Biochemistry, 2014, $68: 1-8$

[10] James Frederickson, Graham Howell. Large-scale 
vermicomposting: emission of nitrous oxide and effects of temperature on earthworm populations: The 7th international symposium on earthworm ecology · Cardiff · Wales · 2002. Original Research Article Pedobiologia. 2003,47 (5-6): 724-730

[11] Chen Chen, Joann K. Whalen, Xiaobin Guo. Earthworms reduce soil nitrous oxide emissions during drying and rewetting cycles. Soil Biology and Biochemistry, 2014, 68: $117-124$

[12] N. R Hulugalle, P. C Entwistle. R. K Mensah. Can lucerne (Medicago sativa L.) strips improve soil quality in irrigated cotton (Gossypium hirsutum L.) fields?.Applied Soil Ecology.1999, 12(1): 81-92

[13] Wenli Kang, Wenting He, LeyuanLi.et al. Characteristics of the soil-like substrates produced with a novel technique combining aerobic fermentation and earthworm treatment. Advances in Space Research, 2012, 50 (11): 1495-1500

[14] Kui Huang, Fusheng Li, Yongfen Wei. et al. Effects of earthworms on physicochemical properties and microbial profiles during vermicomposting of fresh fruit and vegetable wastes. Bioresource Tehnology. 2014, 170: 4552

[15] Timothe B. Parkin, Edwin C. Berry. Microbial nitrogen transformations in earthworm burrows. Soil Biology and Biochemistry. 1999, 31 (13): 1765-1771

[16] Xiaomin Li, Zhong Lin, Chunling Luo.et al. Enhanced microbial degradation of pentachlorophenol from soil in the presence of earthworms: Evidence of functional bacteria using DNA-stable isotope probing. Soil Biology and Biochemistry, 2015, 81: 168-177

[17] Clotilde Sagot, Jean-Jacques Brun, Jean-Luc Grossi. Earthworm distribution and humus forms in the development of a semi-natural alpine spruce forest.European Journal of Soil Biology. 1999, 35 (4):
163-169

[18] J. E Morgan, A. J Morgan. The accumulation of metals $(\mathrm{Cd}, \mathrm{Cu}, \mathrm{Pb}, \mathrm{Zn}$ and $\mathrm{Ca})$ by two ecologically contrasting earthworm species (Lumbricus rubellus and Aporrectodea caliginosa): implications for ecotoxicological testing. Applied Soil Ecology. 1999, 13 (1): 9-20

[19] Xiuchao Song, Manqiang Liu, Di Wu.et al. Heavy metal and nutrient changes during vermicomposting animal manure spiked with mushroom residues. Waste Management.2014, 34 (11): 1977-1983

[20] Blanka Manakova, Jan Kuta, Marketa Svobodova.et al. Effects of combined composting and vermicomposting of waste sludge on arsenic fate and bioavailability.Journal of Hazardous Materials. 2014, 280 (15): 544-551

[21] Surindra Suthar, Poonam Sajwa, Kapi Kumar. Vermiremediation of heavy metals in wastewater sludge from paper and pulp industry using earthworm Eisenia fetida. Ecotoxicology and Environmental Safety. 2014, 109: $177-184$

[22] Martina G Vijver, Jos P. M Vink, Corrnelis J. H Miermans.et al. Oral sealing using glue: a new method to distinguish between intestinal and dermal uptake of metals in earthworms. Soil Biology and Biochemistry, 2003, 35 (1): $125-132$

[23] AUTOFLUORESCENCE AS A TOOL TO STUDY MUCUS SECRETION IN EISENIA FOETIDA R. B. HEREDIA, S. DUENAS.L,

[24] Castillo.et al. Autofluorescence as a tool to study mucus secretion in Eisenia foetida. Comparative Biochemistry and Physiology Part A:Molecular and Integrative Physiology, 2008, 151 (3): 407-414

[25] Weiting Liu, A. Menciassi, S. Scapellato.et al. A biomimetic sensor for a crawling minirobot. Robotics and Autonomous Systems. 2006, 54 (7): 513-528 